\title{
Determination and dietary risk assessment of neonicotinoid and insect growth regulators in honey
}

\author{
Ovokeroye Akpojevwe Abafe $e^{1,2,3}$, Tlou Chokwe $e^{4,5}$ \\ ${ }^{1}$ Chemical Residue Analysis Laboratory, Agricultural Research Council-Onderstepoort Veterinary Research Campus, \\ Onderstepoort, Pretoria 0110, South Africa. \\ ${ }^{2}$ School of Health Sciences, University of KwaZulu-Natal, Durban 4000, South Africa. \\ ${ }^{3}$ School of Geography, Earth and Environmental Sciences, University of Birmingham, Birmingham B15 2TT, \\ United Kingdom. \\ ${ }^{4}$ Scientific Services, Capricorn District Municipality, Polokwane 0699, South Africa. \\ ${ }^{5}$ Department of Environmental Sciences, University of South Africa, Florida 1709, South Africa.
} Correspondence to: Dr. Ovokeroye Akpojevwe Abafe, School of Geography, Earth and Environmental Sciences, University of
Birmingham, Birmingham B15 2TT, United Kingdom. E-mail: Chiralpops@gmail.com

How to cite this article: Abafe OA, Chokwe T. Determination and dietary risk assessment of neonicotinoid and insect growth regulators in honey. J Environ Expo Assess 2021;1:3. https://dx.doi.org/10.20517/jeea.2021.04

Received: 30 Sep 2021 First Decision: 10 Nov 2021 Revised: 29 Nov 2021 Accepted: 6 Dec 2021 Published: 13 Dec 2021

Academic Editor: Stuart Harrad Copy Editor: Yue-Yue Zhang Production Editor: Yue-Yue Zhang

\begin{abstract}
Aim: The aim of this study was to determine the presence, concentrations, dietary intake, and risk of residues of neonicotinoids (NEO) and insect growth regulators (IGR) in commercially available honey in South Africa.
\end{abstract}

Methods: Sample preparation for honey was based on the "dilute and shoot" principle, followed by analysis using an internally validated ultra-high-performance liquid chromatographic coupled to tandem mass spectrometric method. Estimated daily intake and acute and chronic hazard quotients were determined to measure human exposure and health risk to NEO and IGR as well as the risk posed to honeybee.

Results: NEO and IGR were detected in $50 \%$ and $21 \%$ of the 115 honey samples, respectively. The average concentration ranged 0.062-6.50 $\mu \mathrm{gkg}^{-1}$ and $0.479-1.644 \mu \mathrm{gkg}^{-1}$ for NEO and IGR, respectively. While acetamiprid was the most detected (24.35\%) NEO, imidacloprid presented the highest concentration $\left(16.945 \mu \mathrm{g} \mathrm{kg} \mathrm{g}^{-1}\right)$ in a sample. IGR co-occurred at variable concentrations with NEO in honey samples. The estimated daily intakes (EDI) of NEO and IGR ranged from $9.35 \times 10^{-7}$ to $4.93 \times 10^{-6} \mathrm{mg} \mathrm{kg}^{-1} \mathrm{bwd}^{-1}$. The chronic hazard quotient (HQc) and acute hazard quotient $(\mathrm{HQa})$ for NEO and IGR were considerably $<1$, indicating negligible risk to human health and honeybee population. 
Conclusion: A UHPLC-MS/MS method was validated for the simultaneous determination of neonicotinoids and insect growth regulators in honey. Overall, the result of the present study confirms the widespread occurrence of NEO and IGR in honey consumed in South Africa. The EDIs, HQc, and HQa indicate that exposure to all target NEO and IGR via honey consumption constitutes negligible human health risk; however, the consequences of multiple routes of exposure to NEO and IGR cannot be overemphasized.

Keywords: Neonicotinoids, insect growth regulator, honey, dietary risk

\section{INTRODUCTION}

Neonicotinoid insecticides are a class of pesticides that were introduced in the 1990s as replacement for organophosphate pesticides ${ }^{[1-3]}$. Due to their high efficacy for insect control and ease of application, neonicotinoids have quickly become the most widely used insecticides in agriculture, veterinary, and residential environments ${ }^{[4]}$. Based on the actual insecticide consumption, neonicotinoid have a share of approximately $30 \%$ of the global market for insecticides ${ }^{[5,6]}$. They have a similar chemical structure to nicotine, and as such are classified into N-nitroguanidines (i.e., imidacloprid, thiamethoxam, clothianidin, and dinotefuran) and $\mathrm{N}$-cyanoamidines (i.e., acetamiprid and thiacloprid) ${ }^{[4,7]}$. They are characterized by high water solubility [from 185 (thiacloprid) to $4100 \mathrm{mg} / \mathrm{L}$ (thiamethoxam)], which makes them to be readily absorbed by plants either via roots or leaves before being transported throughout the plant tissue ${ }^{[4,8]}$.

The high water solubility of neonicotinoids provides advantage in pest control as they protect the whole plant effectively against boring insects and root-feeding insects ${ }^{[9]}$. The mode of action of these insecticides is to bind to the nicotine acetylcholine receptor agonists, which causes paralysis and death in insects ${ }^{[1,10]}$. Thus, neonicotinoid insecticides use gained application covering many crops from cereals and vegetables to various fruit cultures ${ }^{[11]}$.

Despite their high efficacy, selectivity, and versatile application ${ }^{[4,1,12]}$, there are growing concerns regarding toxicity of neonicotinoid not only to non-target organisms - especially pollinators such as honeybees and wild bees ${ }^{[8,13]}$ as well as other terrestrial and aquatic invertebrates ${ }^{[14]}$ - but also to vertebrates, including humans ${ }^{[15,16]}$. Neonicotinoids toxic effects include mainly reproductive toxicology, neurotoxicity, hepatotoxicity/hepatocarcinogenicity, immunotoxicity, and genetic toxicity ${ }^{[17,18]}$. Studies also showed that neonicotinoids can adversely affect the developing brain especially for children ${ }^{[17-19]}$.

Research shows that neonicotinoids residues can accumulate in pollen and nectar of treated plants, thereby presenting potential risk to pollinators ${ }^{[20]}$. For their survival, bees rely on pollen and nectar sources ${ }^{[21]}$. Nectar is transformed into honey and stored in the hive for daily adult bees and human consumption, which make bees distinctive sentinels of environmental quality ${ }^{[13,21]}$. Thus, the residue concentrations of insecticides in honey can be extrapolated as a measure of contamination in the surrounding environment ${ }^{[22]}$. Due to its high nutritional value, palatable flavor, and medicinal properties, the use of honey has substantially grown and adopted into human consumption habits ${ }^{[23]}$.

In South Africa, about 5000 tons of honey is consumed annually ${ }^{[24]}$. Only $40 \%$ of the total honey consumption is produced locally with China accounting for $80 \%$ of total imported honey for the Country ${ }^{[24]}$. Honey can easily be obtained from a broad range of geographical localities, and studies have reported the presence of neonicotinoid insecticides in honey ${ }^{[10,13,23,25]}$. To protect human and environmental health, the European Union has set maximum residue levels for neonicotinoids in honey (European Data Base, 2019). However, there are few data on the levels of neonicotinoids in honey from the African 
continent ${ }^{[10]}$. To close this gap, this study reports an ultra-high-performance liquid chromatography coupled to tandem mass spectrometry (MS/MS)-based method for the simultaneous determination of neonicotinoid and insect growth regulators in honey. The method was developed, validated, and applied to quantify eight NEO, acetamiprid, clothianidin, dinotefuran, imidacloprid, imidaclothiz, nitenpyram, thiacloprid, and thiamethoxam, and four IGR, buprofezin, cyromazine, fenoxycarb, and triflumuron, in commercially available honey from South Africa. The dietary intake of NEO and IGRs and the risk posed to humans and bees were elucidated.

\section{EXPERIMENTAL}

\section{Chemicals}

Pure standards of eight neonicotinoid insecticides, acetamiprid, clothianidin, dinotefuran, imidacloprid, imidaclothiz, nitenpyram, thiacloprid, and thiamethoxam, and four IGR, buprofezin, cyromazine, fenoxycarb, and triflumuron, as well as two deuterated internal standards, thiamethoxam-D4 and imidacloprid-D4, were products of Dr. Ehrenstorfer GmbH obtained from Industrial Analytical (Pty) Ltd, Johannesburg, South Africa. Microsep (Pty) Ltd, South Africa, supplied mass spectrometry-grade (99.9\%) water and methanol. Ammonium acetate and sodium hydroxide were obtained from Sigma Aldrich, South Africa.

\section{Sampling}

In total, 115 commercially available honey samples were obtained between 2017 and 2020. The samples included both locally produced and imported honey. These samples were collected directly from various establishments under the framework of the national residue-monitoring program. All samples were stored at $4{ }^{\circ} \mathrm{C}$ in the dark prior to analysis. None of the honey samples crystallized before analysis.

\section{Extraction}

Dilute and shoot extraction

Honey samples $(1.0 \pm 0.1 \mathrm{~g})$ were accurately weighed in a $50 \mathrm{~mL}$ polypropylene tube. The sample was spiked with $2 \mathrm{ng} \mathrm{mL} \mathrm{m}^{-1}$ of the mixture of internal standards. This was followed by the addition of $2 \mathrm{~mL}$ each of $10 \mathrm{mM} \mathrm{NaOH}$ and water and $5 \mathrm{~mL}$ of methanol. The mixture was vortex-mixed for 1 min and centrifuged at $5000 \mathrm{rpm}$ for $5 \mathrm{~min}$ in a refrigerated centrifuge kept at $4{ }^{\circ} \mathrm{C}$. Then, a $1 \mathrm{~mL}$ aliquot of the mixture was filtered through $0.22 \mu \mathrm{m}$ PTFE syringe filter into an HPLC vial.

\section{QuEChERS extraction}

One gram of honey was weighed in a $50 \mathrm{~mL}$ centrifuge tube. The sample was spiked with $2 \mathrm{ng} \mathrm{mL}^{-1}$ of the mixture of internal standards and vortexed for $30 \mathrm{~s}$. This was followed by the addition of $10 \mathrm{~mL}$ each of ultrapure water and acetonitrile. The QuEChERS extraction packs comprising of $4 \mathrm{~g} \mathrm{MgSO} 4$ and $1 \mathrm{~g} \mathrm{NaCl}$ were added and dissolved in the mixture by vigorous agitation. The mixture was vortex-mixed for $1 \mathrm{~min}$ and centrifuged at $5000 \mathrm{rpm}$ for $5 \mathrm{~min}$ in a refrigerated centrifuge kept at $4{ }^{\circ} \mathrm{C}$. Approximately $2 \mathrm{~mL}$ of the supernatant were evaporated to insipient dryness using a stream of nitrogen at $30^{\circ} \mathrm{C}$. The residue was reconstituted in $1 \mathrm{~mL}$ of the initial gradient of the mobile phase composition and filtered through a $0.22 \mu \mathrm{m}$ syringe filter into an autosampler vial for ultra-high-performance liquid chromatography (UHPLC)-MS/MS analysis.

\section{Instrumental method}

The chromatographic separation of NEO and IGR was achieved with a Perkin Elmer LX-50 UHPLC system equipped with a Kinetex ${ }^{\otimes} \mathrm{C}_{18} 1.7 \mu \mathrm{m}: 2.1 \times 100 \mathrm{~mm}$ column. The column oven temperature was kept at $50{ }^{\circ} \mathrm{C}$. Separation was achieved with a gradient consisting of $10 \mathrm{mM}$ ammonium acetate in water (A) and methanol (B), at a constant flow rate of $0.4 \mathrm{~mL} \mathrm{~min}^{-1}$. The $\mathrm{LC}$ gradient condition is presented in 
Supplementary Table 1 . Ten microliters of sample was injected onto the LC.

Mass spectrometric identification and confirmation of neonicotinoids was achieved using a PerkinElmer QSight $^{\text {tw }} 220$ triple quadruple mass spectrometer (MS/MS) operated in the positive electrospray ionization mode, with an electrospray voltage set at $4000 \mathrm{~V}$. Nitrogen was used as drying and nebulizer gas, set at 140 and 400 , respectively. The optimized hot surface-induced desolvation temperature was set at $320^{\circ} \mathrm{C}$, while the ion source temperature was set at $350{ }^{\circ} \mathrm{C}$. The acquisition of neonicotinoids was achieved using the time-managed multiple reaction monitoring (MRM) mode. Data were acquired by using Simplicity $3 \mathrm{Q}$ software (version 1.4.1806.29651).

The MS/MS analysis of NEO and IGRs involved the selection of a minimum of two MRM transitions corresponding to the precursor ion or pseudomolecular ion, together with two daughter ions (obtained through direct MS/MS infusion of native standards of individual NEO and IGR). These ions were used to unequivocally confirm and quantify the occurrence of NEO and IGRs. The most intense MRM was selected as the quantitative ion pair, while the second and third MRMs (where available) were utilized as qualitative ion pairs.

\section{Human health risk assessment}

Estimated daily intake and chronic and acute hazard quotients of NEO and IGR to human

The health risk associated with pesticide residues in food usually combines chemical occurrence data with food consumption. In this study, an average body weight of $70 \mathrm{~kg}$ for an adult South African ${ }^{[26]}$ and per capita consumption of $0.21 \mathrm{~g}$ honey per day, based on average annual consumption of 5000 tons of honey by the South African population, were considered ${ }^{[24]}$.

The estimated daily intake (EDI) of each NEO and IGR was calculated following Equation (1):

$$
\operatorname{EDI}\left(\mathrm{mg} \mathrm{kg}^{-1} \mathrm{bw} \mathrm{d}^{-1}\right)=\frac{S T M R \times F I R}{b w}
$$

where STMR is the supervised trial mean residue concentrations for each NEO and IGR $(\mathrm{mg} / \mathrm{kg})$ in this study, FIR is the average daily consumption of honey in South Africa $(0.00021 \mathrm{~kg})$, and bw is the body weight in $\mathrm{kg}$.

The long-term risk to each NEO and IGR was determined by expressing their respective EDIs as a fraction of their corresponding acceptable daily intake (ADI) using Equation (2) and expressed as chronic hazard quotient (HQc).

$$
H Q c=\frac{E D I}{A D I}
$$

To determine the acute dietary exposure risk to human, the estimated short term intake $(\mathrm{mg} / \mathrm{kg})$ of NEO and IGR residues was applied following the method reported by Wang et al. ${ }^{[27]}$, as shown in Equation (3). The acute exposure risk of each NEO and IGR was determined as a fraction of the corresponding acute reference dose (ARfD) and expressed as acute hazard quotient (HQa) [Equation (4)]: 


$$
\begin{aligned}
& E S T I=\frac{L P \times H R}{b w} \\
& H Q a=\frac{E S T I}{A R f D}
\end{aligned}
$$

where LP is the large portion in $\mathrm{kg}$, HR is the maximum residue concentration ( $\mathrm{mg} / \mathrm{kg}$ ), and bw is the body weight in $\mathrm{kg}$. For the estimation of HQa, the LP value of $0.100 \mathrm{~kg}$ honey for the Chinese population was used $^{[27]}$. To the authors' knowledge, there are currently no records of LP for the South African population.

An HQc or HQa > 1 indicates an unacceptable health threat. The lower are the HQc and HQa, the lesser is the risk of chronic and acute exposures.

\section{Risk of neonicotinoids posed to bees}

The hazard assessment of dietary exposure of honeybee foragers and worker nurse bees for the oral exposure to NEO and IGR in honey was estimated. Foragers consume $80 \mathrm{mg}$ of honey while brood nurse bees consume $40 \mathrm{mg}$ of honey per day ${ }^{[10,28]}$. Risk was estimated by incorporating frequency of detection of individual insecticides based on dose ${ }^{[29]}$ and using the average and maximum concentrations of NEO and IGR detected in the honey samples according to Equation (5).

$$
\text { Risk }=\frac{\text { Detection frequency }(\%) \times \text { residue concentration }(\boldsymbol{n g})}{L D_{50}(\mathrm{ng} \text { bee }-1)}
$$

The $\mathrm{LD}_{50}$ values adopted in this study were those reported by Codling et al. ${ }^{[10]}$ and are presented in Table 1 .

\section{Statistical analysis}

Descriptive statistics such as mean, median, and standard deviations and parametric tests such as the analysis of variance were carried out using Microsoft ${ }^{\bullet}$ Excel 2016. Non-parametric statistical analysis was performed using XLSTAT 2019. Only samples with concentration $\geq$ LOQ were considered for the analysis of dietary intake and risk assessment since none of the target NEO and IGR were detected above LOQ in more than $50 \%$ of the samples.

\section{Quality control and quality assurance}

Honey samples that previously tested negative for the target NEO and IGR were used as matrix blanks [Supplementary Figure 1] for the validation experiments and matrix matched calibration curves used for the quantification of target NEO and IGR. Since the use of isotope-labeled internal standards for each of the target neonicotinoids and IGR was not economically feasible, two deuterated (D4) compounds were utilized. The choice of internal standards was based on the relative recovery and relative standard deviation $(n=21)$ obtained for each NEO and IGR. For each batch of analyses, a check standard was analyzed at the beginning and the end of the batch to monitor any drift in retention times of target analytes. Spiked quality control samples $(n=3)$ were analyzed for each batch of analyses to monitor the method performance. Similarly, solvent blanks were analyzed after each sample run to monitor possible carryover. Method blanks $(n=3)$, treated as an unknown samples, were analyzed for each batch of analyses to monitor possible contamination through the analysis. None of the target neonicotinoids and IGRs were detected above $1 \%$ of the concentrations of the least contaminated sample, hence samples were not blank corrected. 
Table 1. Average $\operatorname{LD}_{50}\left(\mathrm{ng}\right.$ bee $\left.{ }^{-1}\right)$ values based on oral exposure of bees reported in the literature ${ }^{[10]}$

\begin{tabular}{ll}
\hline Compound & LD $_{\mathbf{5 0}} \mathbf{n g} \mathbf{b e e}^{-1}$ \\
\hline Cyromazine & 5000 \\
Dinotefuran & 26.8 \\
Acetamiprid & 10,140 \\
Clothianidin & 18 \\
Imidacloprid & 120 \\
Nitenpyrum & 138 \\
Thiamethoxam & 11.8 \\
Fenoxycarb & \\
Triflumuron & 200,000 \\
Buprofezin & \\
Imidaclothiz & \\
\hline
\end{tabular}

\section{RESULTS}

\section{Method development}

Honey is one of the most difficult matrices among foods of animal origin, comprising complex sugars such as monosaccharides, essential oils, dyes, residues of wax and bee pollen, and organic acids. In the analysis of honey, careful sample preparations are invaluable for the determination of pesticide residues such as neonicotinoids and IGRs. The optimized sample preparation method in this study involved the treatment of honey with $10 \mathrm{mM} \mathrm{NaOH}$ solution followed by the addition of water and methanol. Following vortex mixing and centrifugation, $1 \mathrm{~mL}$ of the mixture was filtered through a $0.22 \mu \mathrm{m}$ syringe filter and directly injected onto the UHPLC-MS/MS. The obtained extracts were very clean, resulting in clear chromatographic separation of each of the target analytes [Figure 1].

The suitability of this simple sample preparation method was compared with a QuEChERS method. As shown in Figure 2, this method resulted in better extraction recovery of NEO and IGR compared to QuEChERS.

At least two MRM transitions corresponding to a minimum of four identification points were monitored for each target analyte [Table 2]. The collision energies, entrance voltages, and cell exit potential (CCL2) were individually optimized for each analyte through a flow injection analysis of individual neonicotinoid standard solution [Table 2].

The optimized chromatographic separation of NEO and IGR was achieved by using a Kinetex ${ }^{\otimes} \mathrm{C}_{18}(1.7 \mu \mathrm{m}$ : $2.1 \mathrm{~mm} \times 100 \mathrm{~mm})$ column, which resulted in well-resolved chromatographic peak shape for all target compounds simultaneously [Figure 2]. A mobile phase composition containing $10 \mathrm{mM}$ ammonium acetate in water (aqueous phase) and methanol (organic phase) at a flow rate of $0.4 \mathrm{~mL} \mathrm{~min}^{-1}$ and injection volume of $10 \mu \mathrm{L}$ was found sufficient for the simultaneous determination of NEO and IGR in honey. The retention times [Table 2] were very stable for all target analyte with \%RSD ranging $0.13 \%-1.15 \%(n=21)$.

\section{Method validation}

The analytical method utilized in this study was validated for recovery, precision (repeatability and withinlaboratory reproducibility), linear range, limit of detection (LOD), and limit of quantitation (LOQ). The LOD and LOQ were determined as the lowest detectable concentrations with signal to noise ratio greater than 3 and 10, respectively. The LOQs were verified in spiked matrices and formed part of the concentrations used in the matrix-matched calibration employed for the quantitation of unknown samples. 
Table 2. Optimized MS/MS conditions and retention time of neonicotinoids

\begin{tabular}{|c|c|c|c|c|c|c|c|}
\hline Name & $\begin{array}{l}\text { ESI } \\
\text { polarity }\end{array}$ & $\begin{array}{l}\text { Precursor } \\
(\mathrm{m} / \mathrm{z})\end{array}$ & $\begin{array}{l}\text { Products } \\
(\mathrm{m} / \mathrm{z})\end{array}$ & $\begin{array}{l}\text { Retention time } \\
\text { (min) }\end{array}$ & $\begin{array}{l}\text { Collision } \\
\text { energy }\end{array}$ & $\begin{array}{l}\text { Entrance } \\
\text { voltage }\end{array}$ & $\begin{array}{l}\text { Cell exit } \\
\text { potential }\end{array}$ \\
\hline \multirow[t]{2}{*}{ Acetamiprid } & Positive & 223.2 & 126.1 & 4.37 & -30 & 25 & -49 \\
\hline & & & 99.1 & & -56 & 25 & -73 \\
\hline \multirow[t]{2}{*}{ Clothianidin } & Positive & 250 & 169.1 & 3.99 & -16 & 25 & -39 \\
\hline & & & 132 & & -26 & 25 & -48 \\
\hline \multirow[t]{3}{*}{ Cyromazine } & Positive & 167.2 & 68 & 2.02 & -30 & 25 & -44 \\
\hline & & & 85 & & -30 & 25 & -44 \\
\hline & & & 108 & & -29 & 25 & -43 \\
\hline \multirow[t]{2}{*}{ Dinotefuran } & Positive & 203.1 & 114.1 & 2.34 & -20 & 25 & -38 \\
\hline & & & 129 & & -16 & 25 & -35 \\
\hline \multirow[t]{2}{*}{ Imidacloprid } & Positive & 256.2 & 209 & 3.97 & -18 & 25 & -42 \\
\hline & & & 175.2 & & -26 & 25 & -49 \\
\hline \multirow[t]{2}{*}{ Thiacloprid } & Positive & 253.1 & 126.1 & 4.79 & -26 & 25 & -49 \\
\hline & & & 99.1 & & -60 & 25 & -79 \\
\hline \multirow[t]{2}{*}{ Fenoxycarb } & Positive & 302.2 & 88 & 7.64 & -34 & 25 & -61 \\
\hline & & & 116 & & -15 & 25 & -44 \\
\hline \multirow[t]{2}{*}{ Nitenpyram } & Positive & 271.2 & 126.1 & 2.78 & -35 & 25 & -59 \\
\hline & & & 237.2 & & -25 & 25 & -50 \\
\hline \multirow[t]{2}{*}{ Thiamethoxam } & Positive & 292 & 211 & 3.28 & -18 & 25 & -45 \\
\hline & & & 181 & & -28 & 25 & -54 \\
\hline \multirow[t]{3}{*}{ Triflumuron } & Positive & 359 & 156.2 & 8.4 & -24 & 25 & -58 \\
\hline & & & 139.1 & & -35 & 25 & -67 \\
\hline & & & 285.2 & & -20 & 25 & -54 \\
\hline \multirow[t]{2}{*}{ Buprofezin } & Positive & 306.1 & 201.1 & 11.02 & -18 & 25 & -47 \\
\hline & & & 116.2 & & -24 & 25 & -52 \\
\hline \multirow[t]{2}{*}{ Imidaclothiz } & Positive & 262.1 & 181.2 & 4.18 & -16 & 25 & -45 \\
\hline & Positive & & 122.2 & & -16 & 25 & -45 \\
\hline $\begin{array}{l}\text { Thiamethoxam- } \\
\text { D4 }\end{array}$ & Positive & 295.7 & 214.7 & 3.26 & -18 & 25 & -45 \\
\hline Imidacloprid-D4 & Positive & 260 & 179 & 3.95 & -26 & 25 & -49 \\
\hline
\end{tabular}

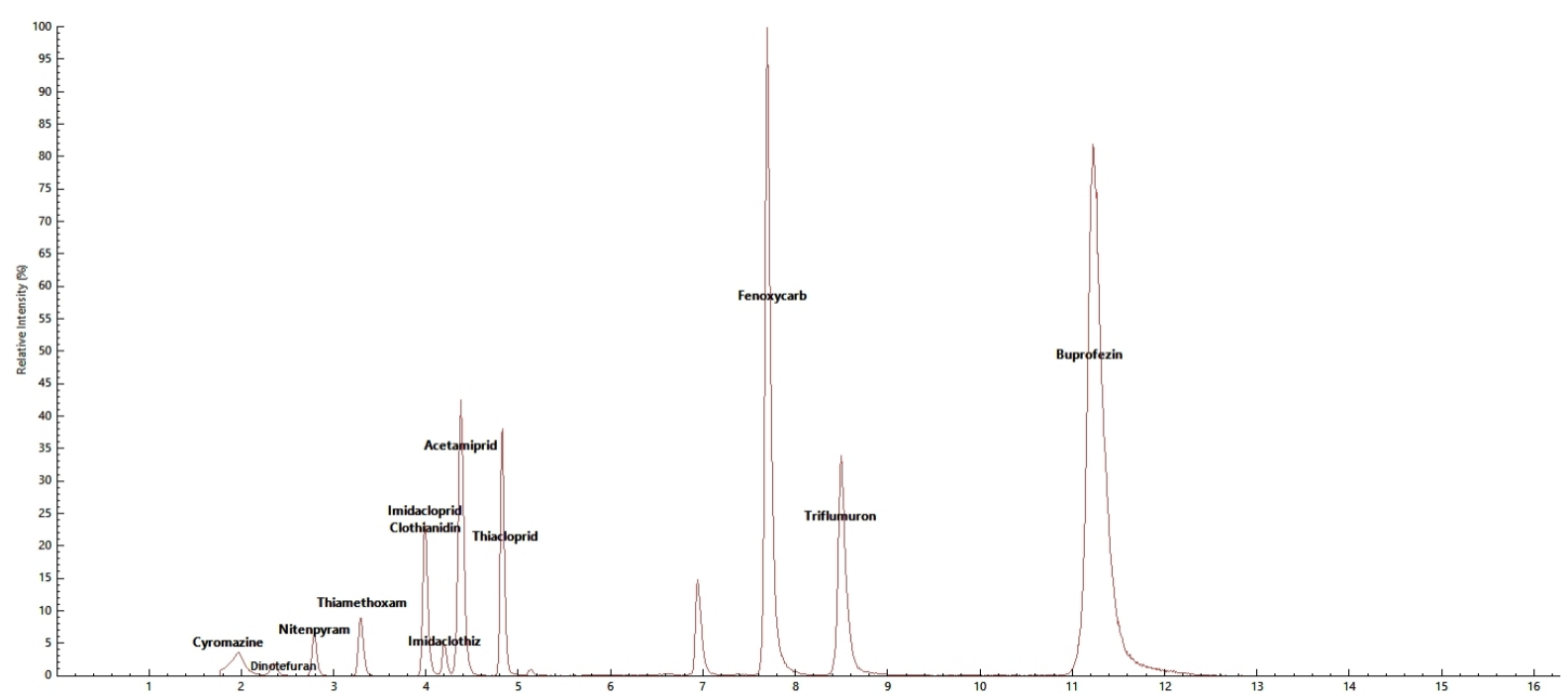

Figure 1. Total ion chromatogram of neonicotinoids and insect growth regulators. 


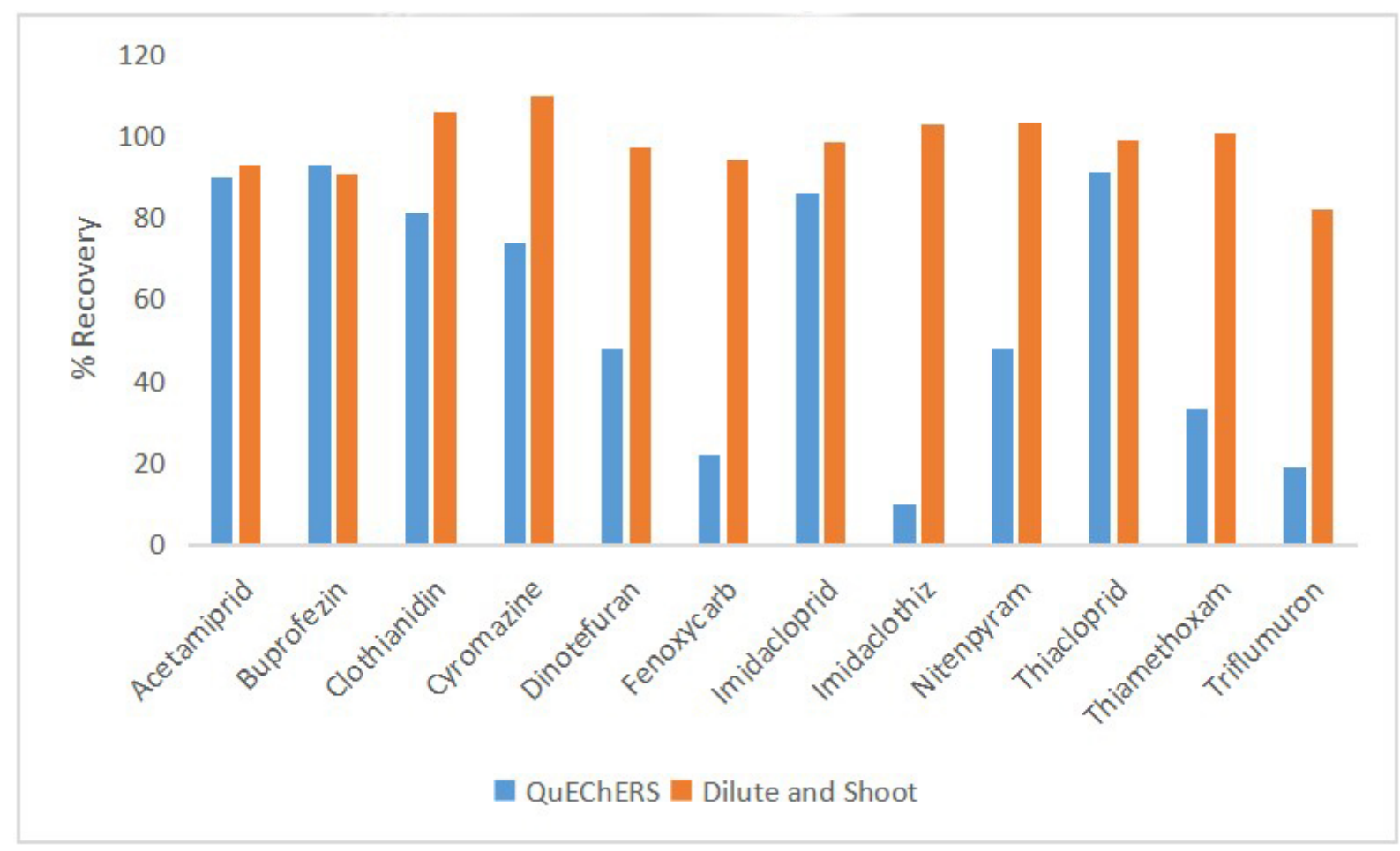

Figure 2. Recovery of neonicotinoids and insect growth regulators using direct extraction method and QuEChERS.

Recoveries and precisions were determined by analysis of replicate samples $(n=21)$ spiked at three different concentrations $\left(0.5,5\right.$, and $\left.10 \mu \mathrm{g} \mathrm{kg}^{-1}\right)$ over a period of three days. The linearity of the method was determined through regression analysis of an eight-point matrix-matched calibration curve in the concentration range of $0.01-10 \mu \mathrm{g} \mathrm{kg}^{-1}$ for each analyte. Table 3 summarizes the method performance.

The recoveries of NEO and IGR at the three validation levels ranged $74 \%-108 \%$ with precision $(\% \mathrm{RSD})<$ $30 \%$ for all target analytes [Figure 3]. The LODs and LOQs of NEO and IGR ranged 0.01-0.03 and 0.01$0.09 \mu \mathrm{g} \mathrm{kg}^{-1}$, respectively. The method was linear over the working range of the calibration curve with coefficient of determination $\left(r^{2}\right)>0.996$ for all target analytes.

\section{Occurrence and concentrations of NEO and IGR in honey}

In total, 115 honey samples were analyzed for the presence of neonicotinoid, as presented in Supplementary Table 2. The descriptive statistics for individual NEO and IGR are presented in Table 4. Approximately 50\% of the samples contained at least one NEO; $8.7 \%$ and 3.5\% of samples contained a combination of two and three NEO each, respectively, while two samples contained a combination of $\geq 4 \mathrm{NEO}$. Acetamiprid was the most detected NEO with detection frequency of $24.4 \%$, while thiacloprid was the least detected (0.87\%). Imidacloprid presented the highest concentration of NEO in any sample $\left(16.945 \mu \mathrm{g} \mathrm{kg}^{-1}\right)$. The detection frequency of NEO was in the order: acetamiprid > clothianidin > dinotefuran $>$ thiomethoxam $>$ imidacloprid $=$ imidaclothiz $>$ nitenpyram $>$ thiacloprid. The mean concentrations $\left(\mu \mathrm{g} \mathrm{kg}^{-1}\right)$ were in the order: clothianidin $(0.315)>$ imidacloprid $(0.283)>$ thiomethoxam $(0.20)>$ dinotefuran $(0.114)>$ nitenpyram $(0.10)>$ acetamiprid $(0.05)>$ imidaclothiz $(0.01)>$ thiacloprid $(<$ LOQ) [Table 4$]$. The concentrations of clothianidin and imidacloprid accounted for $29.3 \%$ and $26.3 \%$ of the total NEO in all samples. Four samples contained NEO concentrations $>10 \mu \mathrm{g} \mathrm{kg}^{-1}$, while $15 \%$ of the samples had NEO concentrations of $1-10 \mu \mathrm{g} \mathrm{kg}^{-1}$. 
Table 3. Summary of validation performance characteristics for neonicotinoids in honey

\begin{tabular}{lllllll}
\hline Neonic & IS & Recovery/\% & RSD/\% & LOD/ $\mathbf{g ~ k g}^{-1}$ & LOQ$/ \boldsymbol{\mu g}_{\mathbf{~ k g}} \mathbf{- 1}^{\mathbf{1}}$ & $\boldsymbol{R}^{\mathbf{2}}$ \\
\hline Acetamiprid & Imidcloprid-D4 & 93 & 14.9 & 0.01 & 0.01 & 0.9997 \\
Buprofezin & Imidcloprid-D4 & 91 & 6.2 & 0.01 & 0.05 & 0.9999 \\
Clothianidin & Thiomethoxam-D4 & 111 & 13.9 & 0.01 & 0.01 & 0.9998 \\
Cyromazine & Thiomethoxam-D4 & 110 & 15 & 0.01 & 0.05 & 0.9997 \\
Dinetofuran & Thiomethoxam-D4 & 97 & 16.4 & 0.03 & 0.05 & 0.9972 \\
Fenoxycarb & Imidcloprid-D4 & 94 & 9.4 & 0.01 & 0.05 & 0.9996 \\
Imidaclothiz & Thiomethoxam-D4 & 103 & 10.3 & 0.03 & 0.09 & 0.9975 \\
Imidacloprid & Imidcloprid-D4 & 98 & 8.9 & 0.01 & 0.05 & 0.9999 \\
Nitenpyram & Thiomethoxam-D4 & 103 & 7 & 0.03 & 0.09 & 0.9996 \\
Thiacloprid & Imidcloprid-D4 & 99 & 14.6 & 0.01 & 0.05 & 0.9998 \\
Thiamethoxam & Thiamethoxam-D4 & 100 & 10.9 & 0.01 & 0.05 & 0.9998 \\
Triflumuron & Imidcloprid-D4 & 81 & 12.7 & 0.03 & 0.09 & 0.9996 \\
\hline
\end{tabular}

Insect growth regulators were detected and quantified in $21 \%$ of the 115 honey samples in this study. While cyromazine $(\sim 14 \%)$ was the most frequently detected IGR, triflumuron was detected at higher concentrations. The relative abundance of IGR was in the order: cyromazine $>$ triflumuron $>$ buprofezin $>$ fenoxycarb. The concentrations ranged $<$ LOQ-0.801, $<$ LOQ-1.456, $<$ LOQ-1.524, and $<$ LOQ-11.304 $\mu \mathrm{g} \mathrm{kg}^{-1}$, respectively, for buprofezin, cyromazine, fenoxycarb, and triflumuron. Only one honey sample contained IGR concentration of $>10 \mu \mathrm{gg}^{-1}$ for triflumuron. Four honey samples contained all four IGR, one sample contained three IGR, and three honey samples had at least two IGR.

The EDIs of NEO and IGR ranged from $1.86 \times 10^{-10}$ to $1.95 \times 10^{-8}$ and $9.35 \times 10^{-10}$ to $4.93 \times 10^{-9} \mathrm{mg} \mathrm{kg}^{-1} \mathrm{bwd}^{-1}$, respectively [Table 5]. While imidacloprid and triflumuron were the highest contributors to the total EDIs of NEO and IGR, thiacloprid and buprofezin made the least contributions to the total EDIs.

The HQc of the target NEO and IGR in this study ranged from $9.93 \times 10^{-6}$ to $1.07 \times 10^{-4}$ and $2.71 \times 10^{-5}$ to $3.52 \times 10^{-4}$, respectively [Table 5]. The acute exposures of NEO and IGR were estimated as a fraction of their respective ARfDs using the maximum concentrations of each compound measured and the consumption of honey ${ }^{[27]}$. The HQa of NEO and IGR ranged from $2.95 \times 10^{-6}$ to $6.05 \times 10^{-5}$ and $1.09 \times 10^{-6}$ to $2.1 \times 10^{-5}$, respectively.

\section{Dietary risk to bees}

The dietary risk of NEO and IGR to forager and nurse bees is presented in Table 6. Clothianidin, imidacloprid, thiamethoxam, and dinotefuran presented more risk to forager and nurse bees than the other target NEO and IGRs in this study.

\section{DISCUSSION}

\section{Occurrence of NEO and IGR in honey}

Five active ingredients of NEO, namely acetamiprid, clothianidin, imidacloprid, thiacloprid, and thiamethoxam, are currently registered under over 100 trade names in South Africa. These active ingredients are used on several crops including maize, oats, peaches, apples, barley, cotton seed, canola, citrus, grapes, cucurbits, sunflower seeds, sorghum, wheat, and tomatoes ${ }^{[30]}$.

The average detection frequency of NEO in the honey samples in this study (49.6\%) was generally lower than the global average of $75 \%^{[21]}$ and the American average of $90 \%^{[1]}$; however, this frequency of detection 
Table 4. Descriptive statistics of NEO and IGR in honey

\begin{tabular}{|c|c|c|c|c|c|c|c|c|c|c|c|c|}
\hline Descriptive statistics & Acetamiprid & Buprofezin & Clothianidin & Cyromazine & Dinotefuran & Fenoxycarb & Imidacloprid & Imidaclothiz & Nitenpyram & Thiacloprid & Thiamethoxam & Triflumuron \\
\hline Sum & 6.487 & 2.181 & 36.196 & 9.517 & 11.440 & 2.396 & 32.503 & 1.025 & 11.299 & 0.062 & 22.913 & 21.368 \\
\hline Mean & $<$ LOQ & $<\mathrm{LOQ}$ & 0.002 & 0.001 & 0.001 & $<$ LOQ & 0.007 & $<$ LOQ & 0.003 & $<\mathrm{LOQ}$ & 0.003 & 0.002 \\
\hline Median & 0.075 & 0.054 & 0.197 & 0.504 & 0.890 & 0.067 & 0.491 & 0.069 & 2.365 & 0.062 & 1.817 & 0.223 \\
\hline Minimum & 0.008 & 0.033 & 0.032 & 0.424 & 0.384 & 0.050 & 0.310 & 0.021 & 0.637 & 0.062 & 0.386 & 0.026 \\
\hline Maximum & 1.975 & 0.801 & 14.020 & 1.456 & 3.094 & 1.524 & 16.945 & 0.706 & 5.933 & 0.062 & 8.500 & 11.379 \\
\hline Detection frequency (\%) & 24.4 & 6.1 & 18.3 & 14 & 9.0 & 4.3 & 4.3 & 4.3 & 3.5 & 0.9 & 7.0 & 11.3 \\
\hline 95 percentile & 0.815 & 0.782 & 12.532 & 1.023 & 2.529 & 1.359 & 16.436 & 0.606 & 5.422 & 0.062 & 7.478 & 9.218 \\
\hline
\end{tabular}

95 percentile 0.815

exceeded the $40.8 \%$ recently reported in China ${ }^{[27]}$. The profile of NEO recorded in this study is in tandem with the high volume use of five active ingredients of $\mathrm{NEO}$, which are currently registered in over 130 products available for use in South Africa ${ }^{[31]}$. Interestingly, the profiles of NEO in this study were similar to those reported in China, whereby acetamiprid and imidacloprid had the highest detection frequency and highest detection concentration in sample, respectively ${ }^{[27]}$. This observation is not surprising as $>60 \%$ of honey consumed in South Africa originates from China ${ }^{[24]}$. Only two honey samples exceeded the maximum residue limit (MRL) for clothianidin (i.e., MRL $=10 \mu \mathrm{g} \mathrm{kg}^{-1}$ ). This is a concern considering the toxicity of clothianidin to honeybees. Both thiamethoxam and imidacloprid are used in seed dressing of maize to control the black maize beetle Heteronychus arator in South Africa ${ }^{[31]}$.

The profile of NEO detected in these samples were different from those reported across the European Union, in which thiacloprid and thiamethoxam were the dominant NEO found in honey ${ }^{[11]}$. Whereas only about $4.3 \%$ of the samples in this study contained imidacloprid, a recent study found imidacloprid in $27 \%$ of Irish honey samples. Prevailing landscape, land use, bee species, pesticide governance, and floral origin are some of the factors responsible for the residue profile of NEO in honey from different countries and geographical regions ${ }^{[25]}$.

The use of both imidacloprid and clothianidin has been restricted in the European Union since 2013 (EC, 2018). Studies conducted around the globe showed low detection frequency of insecticides in honey ${ }^{[23]}$. A study by Codling et al. ${ }^{[10]}$ reported detection frequencies of $19 \%$, $8 \%$, $3 \%$, and $38 \%$ for acetamiprid, imidacloprid, thiamethoxam, and dinotefuran, respectively, in honey from Egypt. In Australia, Ligor et al. ${ }^{[25]}$ reported concentrations of neonicotinoids in excess of $1350 \mathrm{ng} \mathrm{g}^{-1}$ for thiamethoxam in three honey samples.

The levels of IGR detected in these samples were considerably lower than concentrations reported in honey from China ${ }^{[32]}$. It was observed that certain NEO, for example, acetamiprid, clothianidin, dinotefuran, and imidacloprid, occurred frequently with IGR in the same honey samples. IGR have been rarely reported in honey; however, they have been measured in cabbage ${ }^{[33]}$, citrus ${ }^{[34]}$, Chinese traditional herbs ${ }^{[35]}$, and animal tissues ${ }^{[36]}$. Triflumuron is a registered IGR for use in mangoes, peaches, apples, and pears in South Africa; hence, the high concentration of this IGR in honey could be associated with its widespread 
Table 5. Summary of daily intake and risk associated with human exposure to NEO and IGR

\begin{tabular}{|c|c|c|c|c|c|c|}
\hline NEO/IGR & ADI/ $\mathrm{mg} \mathrm{kg}^{-1} \mathrm{bwd}^{-1}$ & ARfD/ $\mathrm{mg} \mathrm{kg}^{-1}$ bw & EDI/mg kg ${ }^{-1}$ bwd $^{-1}$ & $\mathrm{ESTI} / \mathrm{mg} \mathrm{kg}^{-1}$ & HQc & $\mathrm{HQa}$ \\
\hline Acetamiprid & 0.07 & 0.1 & $6.95036 \mathrm{E}-07$ & $2.82 \times 10^{-6}$ & $9.92908 \mathrm{E}-06$ & $2.82143 \mathrm{E}-05$ \\
\hline Buprofezin & 0.01 & 0.5 & $9.34714 \mathrm{E}-07$ & $1.14 \times 10^{-6}$ & $9.34714 \mathrm{E}-05$ & $2.28857 \mathrm{E}-06$ \\
\hline Clothianidin & 0.1 & 0.6 & 5.17086E-06 & $2.0 \times 10^{-5}$ & 5.17086E-05 & $3.3381 E-05$ \\
\hline Cyromazine & 0.06 & 0.1 & $1.78444 \mathrm{E}-06$ & $2.08 \times 10^{-6}$ & 2.97406E-05 & $2.08 \mathrm{E}-05$ \\
\hline Dinotefuran & 0.2 & 1 & $3.43 \mathrm{E}-06$ & $4.42 \times 10^{-6}$ & $1.76 \mathrm{E}-05$ & $4.42 \mathrm{E}-06$ \\
\hline Fenoxycarb & 0.053 & 2 & $1.4376 \mathrm{E}-06$ & $2.18 \times 10^{-6}$ & $2.71245 \mathrm{E}-05$ & 1.08857E-06 \\
\hline Imidacloprid & 0.06 & 0.4 & $1.95018 \mathrm{E}-05$ & $2.42 \times 10^{-5}$ & 3.25E-04 & 6.05179E-05 \\
\hline Imidaclothiz & 0.025 & & $6.15 \mathrm{E}-07$ & $1.0 \times 10^{-6}$ & $2.46 \mathrm{E}-05$ & \\
\hline Nitenpyram & 0.53 & & 8.47425E-06 & $8.48 \times 10^{-6}$ & $1.59892 \mathrm{E}-05$ & \\
\hline Thiacloprid & 0.01 & 0.03 & $1.86 \mathrm{E}-07$ & $8.86 \times 10^{-8}$ & $1.86 \mathrm{E}-05$ & $2.95238 \mathrm{E}-06$ \\
\hline Thiamethoxam & 0.08 & 1 & 8.59238E-06 & $1.21 \times 10^{-5}$ & 1.07E-04 & $1.21429 \mathrm{E}-05$ \\
\hline Triflumuron & 0.014 & & 4.93108E-06 & $1.63 \times 10^{-5}$ & $3.52 \mathrm{E}-04$ & \\
\hline
\end{tabular}

Table 6. Dietary risk of neonicotinoid to bees (ng/bee) via honey ingestion

\begin{tabular}{lllll}
\hline Compound & $\begin{array}{l}\text { Foragers } \\
\text { Average }\end{array}$ & Maximum & $\begin{array}{l}\text { Nurse } \\
\text { Average }\end{array}$ & Maximum \\
\hline Cyromazine & $1.98 \mathrm{E}-08$ & $3.5 \mathrm{E}-06$ & $9.9 \mathrm{E}-09$ & $1.75 \mathrm{E}-06$ \\
Dinotefuran & $2.7 \mathrm{E}-5$ & $7.5 \mathrm{E}-04$ & $1.35 \mathrm{E}-05$ & $3.75 \mathrm{E}-04$ \\
Acetamiprid & $3.9 \mathrm{E}-08$ & $7.8 \mathrm{E}-05$ & $1.95 \mathrm{E}-08$ & $3.9 \mathrm{E}-05$ \\
Clothianidin & $1.2 \mathrm{E}-05$ & $3.5 \mathrm{E}-04$ & $6 \mathrm{E}-06$ & $1.75 \mathrm{E}-04$ \\
Imidacloprid & $1.3 \mathrm{E}-05$ & $7.9 \mathrm{E}-04$ & $6.5 \mathrm{E}-06$ & $3.95 \mathrm{E} 04$ \\
Nitenpyrum & $2.5 \mathrm{E}-06$ & $8.6 \mathrm{E}-05$ & $1.25 \mathrm{E}-06$ & $4.3 \mathrm{E}-05$ \\
Thiamethoxam & $2 \mathrm{E}-05$ & $7.9 \mathrm{E}-04$ & $1 \mathrm{E}-05$ & $3.95 \mathrm{E}-04$ \\
Triflumuron & $4 \mathrm{E}-09$ & $4 \mathrm{E}-07$ & $2 \mathrm{E}-09$ & $2 \mathrm{E}-07$ \\
\hline
\end{tabular}

use. Overall, the result of the present studies confirms the widespread occurrence of neonicotinoid and insect growth regulators in honey consumed in South Africa. The synergistic effects of these co-occurring compounds in honey could pose a risk to non-target organisms such as bees and human health.

\section{Dietary intakes of NEO and IGR via honey consumption}

The EDIs of each NEO and IGR were several orders of magnitude lower than their respective ADIs. Recent studies have mostly employed the use of the mean concentrations of pesticide residues rather than the median concentrations, because it was found to be mostly higher and could represent the worst-case scenario $^{[27]}$.

Generally, the HQc and HQa reported in this study were several orders of magnitude lower than values reported in honey and other food commodities in China and other parts of the world ${ }^{[27,37]}$.

Overall, the EDIs, HQc, and HQa of NEO and IGR in honey consumed in South Africa indicate that the consumption of honey does not currently pose any risk of adverse effects of NEO and IGR to human in South Africa.

The dietary risk of NEO and IGR to forager and nurse bees is presented in Table 5. The obtained result shows negligible risks of neonicotinoids and IGR toward bees (risk $<0.01$ ) for all the analytes for both the mean concentration and the highest concentration detected. Thiamethoxam, acetamiprid, and dinotefuran 


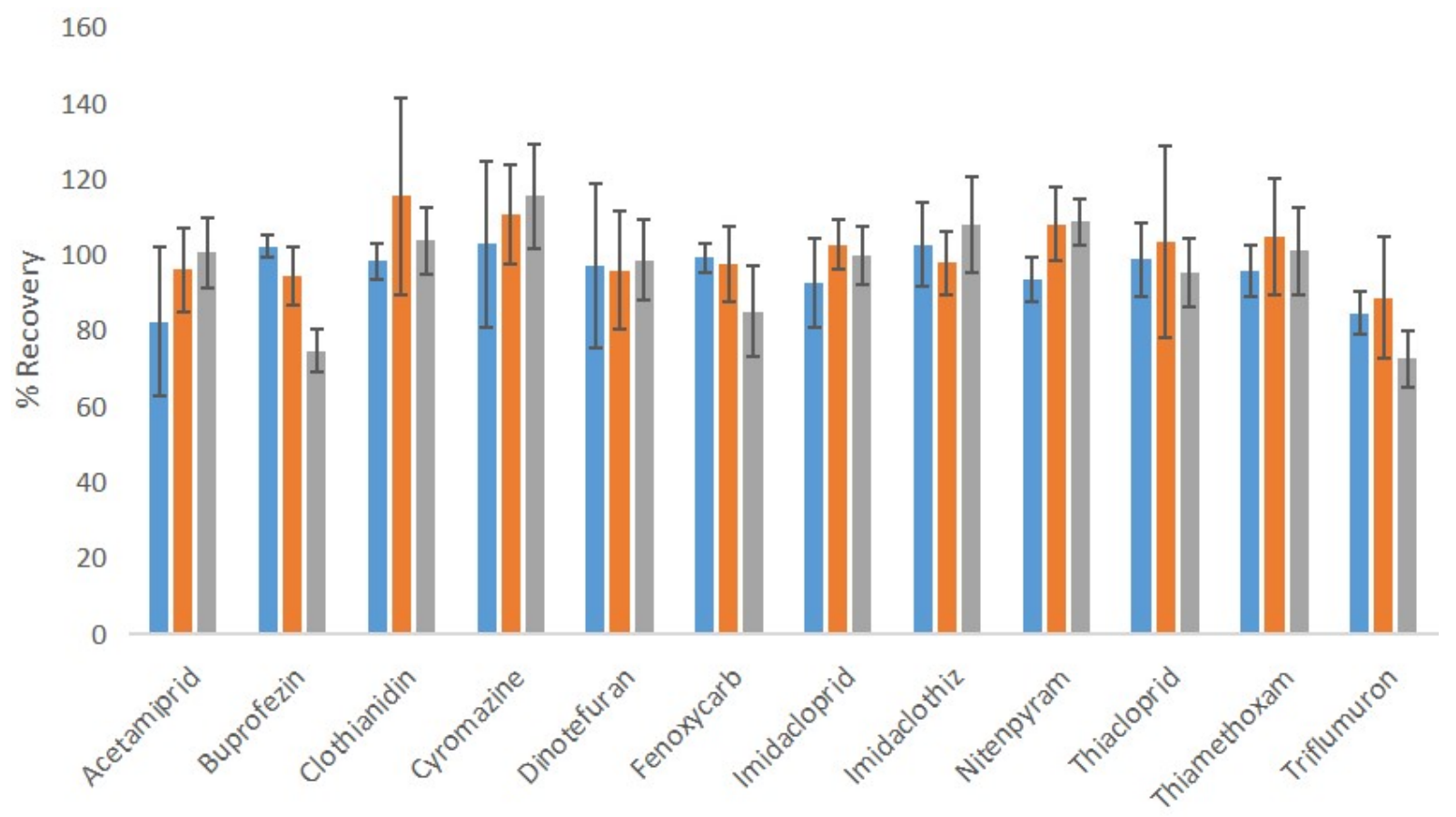

Neonicotinoid and Insect Growth Regulator

$0.5 \mu \mathrm{gkg}-1 \square 5 \mu \mathrm{gkg}-1=10 \mu \mathrm{gkg}-1$

Figure 3. Recovery and within-laboratory reproducibility of neonicotinoids and insect growth regulator.

showed similar risk at maximum concentrations for both the foragers and nurse bees, albeit at a negligible risk category (risk < 0.01).

The congeners of NEO with reported residues were in tandem with their bee toxicities. Acetamiprid was the most frequently detected NEO in the samples, while imidacloprid was detected at the highest concentration for any single honey sample in this study. These two NEO have relatively low toxicities to bees, as shown by their acute oral $\mathrm{LD}_{50}$ of 10,140 and $120 \mathrm{ng} /$ bee, for acetamiprid and imidacloprid, respectively [Table 1]. Hence, it can be deduced that honeybees are not exposed to lethal doses of these NEO during foraging, thus able to transport acetamiprid and imidacloprid into beehives. In contrast, three of the frequently detected NEO in the honey samples - clothianidin, dinotefuran and thiamethoxam - are highly toxic to bees with their reported oral $\mathrm{LD}_{50}$ of $18,26.8$, and $11.8 \mathrm{ng} / \mathrm{bee}$, respectively ${ }^{[10]}$. The exposure of foraging honeybees to small doses of these highly toxic NEO could lead to the death of bees before they can transfer these compounds into honey ${ }^{[11]}$. Bee colony collapse has been reported at various times in South Africa. A study by Pirk et al. ${ }^{[38]}$ reported an average bee colony loss of $29 \%$ between 2009 and 2010 . This was attributed to small hive beetles, absconding, varroa mite, and chalkbrood disease ${ }^{[38]}$. However, a recent BBC report associated the loss of over one million bees in South Africa in 2018 to the insecticide Fiprinol, used by wine farmers ${ }^{[39]}$. Imidacloprid poisoning in granivorous Cape spurfowl (Pternistis capensis) was recently reported in South Africa following the ingestion of imidacloprid-treated wheat and barley seeds sown in a field in South Africa ${ }^{[40]}$. This poisoning resulted in severe neurological abnormalities and eventual deaths of several non-target organisms such as Pternistis capensis and Francolinus africanus (Greywing francolin) ${ }^{[40]}$. 


\section{CONCLUSION}

A simple analytical method was developed and validated in this study. The method satisfied regulatory requirements for the monitoring of NEO and IGR in honey (SANCO/10684/2009).

This study provides background data on the occurrence of neonicotinoid and insect growth regulators in commonly consumed honey in South Africa. The concentrations of NEO and IGR found in honey indicate negligible risk to human and bee health.

Future studies focusing on the identification of the exact sources of NEO and IGR as well as the risk posed to the honeybee population in South Africa are encouraged; studies on the human health risk associated with multiple dietary and non-dietary exposure routes of mixtures of these compounds cannot be overemphasized.

\section{DECLARATIONS}

\section{Acknowledgments}

The authors are grateful to the Agricultural Research Council of South Africa for financial support. The authors are grateful to Ms. Maropeng Letsoalo and Ms Linda Macheka for assistance with sample preparation.

\section{Authors' contributions}

Made substantial contributions to conception and design of the study, funding, and performed data analysis and interpretation: Abafe OA

Performed data acquisition, as well as provided administrative, technical, and material support: Abafe OA, Chokwe T

\section{Availability of data and materials}

Additional data for this study are presented in the supplementary information.

\section{Financial support and sponsorship}

This study was supported in part by the Agricultural Research Council under Project P10000137.

\section{Conflicts of interest}

Both authors declared that there are no conflicts of interest.

\section{Ethical approval and consent to participate}

Not applicable.

\section{Consent for publication}

Not applicable.

\section{Copyright}

(c) The Author(s) 2021.

\section{REFERENCES}

1. Chen M, Tao L, McLean J, Lu C. Quantitative analysis of neonicotinoid insecticide residues in foods: implication for dietary exposures. J Agric Food Chem 2014;62:6082-90. DOI PubMed PMC

2. Hook SE, Doan H, Gonzago D, et al. The impacts of modern-use pesticides on shrimp aquaculture: an assessment for north eastern Australia. Ecotoxicol Environ Saf 2018;148:770-80. DOI PubMed

3. English SG, Sandoval-Herrera NI, Bishop CA, et al. Neonicotinoid pesticides exert metabolic effects on avian pollinators. Sci Rep 2021;11:2914. DOI PubMed PMC 
4. Pietrzak D, Kania J, Kmiecik E, Malina G, Wątor K. Fate of selected neonicotinoid insecticides in soil-water systems: current state of the art and knowledge gaps. Chemosphere 2020;255:126981. DOI PubMed

5. Baron GL, Raine NE, Brown MJF. General and species-specific impacts of a neonicotinoid insecticide on the ovary development and feeding of wild bumblebee queens. Proc Biol Sci 2017;284:20170123. DOI PubMed PMC

6. Zhang Y, Chen D, Du M, et al. Insights into the degradation and toxicity difference mechanism of neonicotinoid pesticides in honeybees by mass spectrometry imaging. Sci Total Environ 2021;774:145170. DOI PubMed

7. Jeschke P, Nauen R, Schindler M, Elbert A. Overview of the status and global strategy for neonicotinoids. J Agric Food Chem 2011;59:2897-908. DOI PubMed

8. Goulson D, Kleijn D. REVIEW: an overview of the environmental risks posed by neonicotinoid insecticides. $J$ Appl Ecol 2013;50:97787. DOI

9. Wood TJ, Goulson D. The environmental risks of neonicotinoid pesticides: a review of the evidence post 2013. Environ Sci Pollut Res Int 2017;24:17285-325. DOI PubMed PMC

10. Codling G, Naggar YA, Giesy JP, Robertson AJ. Neonicotinoid insecticides in pollen, honey and adult bees in colonies of the European honey bee (Apis mellifera L.) in Egypt. Ecotoxicology 2018;27:122-31. DOI PubMed

11. Tanner G, Czerwenka C. LC-MS/MS analysis of neonicotinoid insecticides in honey: methodology and residue findings in Austrian honeys. J Agric Food Chem 2011;59:12271-7. DOI PubMed

12. Buszewski B, Bukowska M, Ligor M, Staneczko-Baranowska I. A holistic study of neonicotinoids neuroactive insecticides-properties, applications, occurrence, and analysis. Environ Sci Pollut Res Int 2019;26:34723-40. DOI PubMed PMC

13. Proietto Galeano M, Scordino M, Sabatino L, et al. UHPLC/MS-MS analysis of six neonicotinoids in honey by modified QuEChERS: method development, validation, and uncertainty measurement. Int J Food Sci 2013;2013:863904. DOI PubMed PMC

14. Fairbrother A, Purdy J, Anderson T, Fell R. Risks of neonicotinoid insecticides to honeybees. Environ Toxicol Chem 2014;33:719-31. DOI PubMed PMC

15. Cimino AM, Boyles AL, Thayer KA, Perry MJ. Effects of neonicotinoid pesticide exposure on human health: a systematic review. Environ Health Perspect 2017;125:155-62. DOI PubMed PMC

16. Basley K, Goulson D. Neonicotinoids thiamethoxam and clothianidin adversely affect the colonisation of invertebrate populations in aquatic microcosms. Environ Sci Pollut Res Int 2018;25:9593-9. DOI PubMed PMC

17. Bal R, Naziroğlu M, Türk G, et al. Insecticide imidacloprid induces morphological and DNA damage through oxidative toxicity on the reproductive organs of developing male rats. Cell Biochem Funct 2012;30:492-9. DOI PubMed

18. Han W, Tian Y, Shen X. Human exposure to neonicotinoid insecticides and the evaluation of their potential toxicity: an overview. Chemosphere 2018;192:59-65. DOI PubMed

19. Kimura-Kuroda J, Komuta Y, Kuroda Y, Hayashi M, Kawano H. Nicotine-like effects of the neonicotinoid insecticides acetamiprid and imidacloprid on cerebellar neurons from neonatal rats. PLoS One 2012;7:e32432. DOI PubMed PMC

20. Iwasa T, Motoyama N, Ambrose JT, Roe R. Mechanism for the differential toxicity of neonicotinoid insecticides in the honey bee, Apis mellifera. Crop Protection 2004;23:371-8. DOI

21. Mitchell EAD, Mulhauser B, Mulot M, Mutabazi A, Glauser G, Aebi A. A worldwide survey of neonicotinoids in honey. Science 2017;358:109-11. DOI PubMed

22. Greenleaf SS, Williams NM, Winfree R, Kremen C. Bee foraging ranges and their relationship to body size. Oecologia 2007;153:58996. DOI PubMed

23. Souza APF, Petrarca MH, de Campos Braga PA, Rodrigues NR, Reyes FGR. Analysis of insecticide residues in honey by liquid chromatography tandem mass spectrometry using QuEChERS optimized by the Plackett Burman design. CyTA - Journal of Food 2021;19:326-32. DOI

24. Kala Z. Sweetie, do you know where your honey comes from? Available from: https://www.foodformzansi.co.za/sweetie-do-youknow-where-your-honey-comes-from/ [Last accessed on 13 Dec 2021].

25. Ligor M, Bukowska M, Ratiu IA, Gadzała-Kopciuch R, Buszewski B. Determination of neonicotinoids in honey samples originated from poland and other world countries. Molecules 2020;25:5817. DOI PubMed PMC

26. Abafe OA, Macheka LR, Abafe OT, Chokwe TB. Concentrations and human exposure assessment of per and polyfluoroalkyl substances in farmed marine shellfish in South Africa. Chemosphere 2021;281:130985. DOI PubMed

27. Wang X, Goulson D, Chen L, et al. Occurrence of neonicotinoids in Chinese apiculture and a corresponding risk exposure assessment. Environ Sci Technol 2020;54:5021-30. DOI PubMed

28. Rortais A, Arnold G, Halm M, Touffet-briens F. Modes of honeybees exposure to systemic insecticides: estimated amounts of contaminated pollen and nectar consumed by different categories of bees. Apidologie 2005;36:71-83. DOI

29. Sanchez-Bayo F, Goka K. Pesticide residues and bees--a risk assessment. PLoS One 2014;9:e94482. DOI PubMed PMC

30. Quinn L, B, de J, et al. Pesticide use in South Africa: one of the largest importers of pesticides in Africa. In: Stoytcheva M, editor. Pesticides in the Modern World - Pesticides Use and Management. InTech; 2011. DOI

31. Academy of Science of South Africa (ASSAf). Neonicotinoids and their Impact on Ecosystem Services for Agriculture and Biodiversity in Africa. Network of African Science Academies (NASAC); 2019. DOI

32. Song S, Zhang C, Chen Z, et al. Simultaneous determination of neonicotinoid insecticides and insect growth regulators residues in honey using LC-MS/MS with anion exchanger-disposable pipette extraction. J Chromatogr A 2018;1557:51-61. DOI PubMed

33. Hu JY, Deng ZB, Qin DM. Determination of diacylhydrazines-type insect growth regulator JS-118 residues in cabbage and soil by high performance liquid chromatography with DAD detection. Bull Environ Contam Toxicol 2009;83:803-7. DOI PubMed

34. Payá P, Oliva J, Zafrilla P, Cámara MA, Barba A. Bioavailability of insect growth regulator residues in citrus. Ecotoxicology 
2009;18:1137-42. DOI PubMed

35. Qian M, Wu L, Zhang H, et al. Determination of 16 insect growth regulators in edible Chinese traditional herbs by liquid chromatography electrospray tandem mass spectrometry. Anal Bioanal Chem 2012;402:2451-62. DOI PubMed

36. Hou X, Zhou D, Huai W, et al. Simultaneous determination of cyromazine and dicyclanil in animal edible tissues using UPLCMS/MS. Food Addit Contam Part A Chem Anal Control Expo Risk Assess 2013;30:660-5. DOI PubMed

37. Cui K, Wu X, Wei D, et al. Health risks to dietary neonicotinoids are low for Chinese residents based on an analysis of 13 dailyconsumed foods. Environ Int 2021;149:106385. DOI PubMed

38. Pirk CWW, Human H, Crewe RM, van Engelsdorp D. A survey of managed honey bee colony losses in the Republic of South Africa-2009 to 2011. Journal of Apicultural Research 2015;53:35-42. DOI

39. British Broadcasting Corporation, BBC. South African bees: 'One million die in Cape Town'. Available from: https://www.bbc.co.uk/news/world-africa-46345127 [Last accessed on 10 Dec 2021]. DOI

40. Botha CJ, Du Plessis EC, Coetser H, Rosemann M. Analytical confirmation of imidacloprid poisoning in granivorous Cape spurfowl (Pternistis capensis). J S Afr Vet Assoc 2018;89:e1-5. DOI PubMed PMC 